\section{Decorticate Posturing}

Jacob Kean ${ }^{1}$ and Travis Williams ${ }^{2}$

${ }^{1}$ Department of Physical Medicine and

Rehabilitation, Indiana University School of

Medicine, Indianapolis, IN, USA

${ }^{2}$ Department of Physical Medicine and

Rehabilitation, Indiana University, Indianapolis,

IN, USA

\section{Synonyms}

Flexor posturing

\section{Definition}

Decorticate posturing is a pattern of movement produced by extensive lesions in white matter, internal capsule, or thalamus and characterized by rigidity; flexion of the arms, fists, and fingers; and extension of the legs. Decorticate (or flexor) posturing may be partial or asymmetric and is distinguished from decerebrate (or extensor) posturing by the flexion in the arms, which positions the hands close to the heart.

\section{Cross-References}

Decerebrate Posturing

\section{References and Readings}

Posner, J. B., Saper, C. B., Schiff, N. D., \& Plum, F. (2007). Plum and Posner's diagnosis of stupor and coma. New York: Oxford University Press. 